\section{'Trinidad Moruga Scorpion' Pepper is the World's Hottest Measured Chile Pepper at More Than Two Million Scoville Heat Units}

\author{
Paul W. Bosland ${ }^{1}$, Danise Coon, and Gregory Reeves
}

AdDITIONAL INDEX WORDs. capsaicinoids, Capsicum chinense, HPLC, landrace, pungency, RAPD

Summary. This study established the heat levels for several high-heat chile pepper (Capsicum chinense) varieties (Trinidad Moruga Scorpion, Bhut Jolokia, Trinidad Scorpion, Douglah Trinidad Chocolate, and Trinidad 7-pot Jonah) to determine which variety has the highest average measured heat level and the relatedness of the chile peppers using molecular analysis. In replicated trials with appropriate controls at Las Cruces, NM, results show two 'Trinidad Moruga Scorpion' chile pepper plants reached more than two million Scoville heat units (SHU). This is the first confirmation of chile pepper fruit measuring more than two million SHU. A large range of heat levels was observed among the field plots-further supporting strong environmental effects on chile pepper pungency. 'Trinidad Moruga Scorpion' was significantly hotter than 'Bhut Jolokia', but 'Trinidad 7-pot Jonah', 'Douglah Trinidad Chocolate', and 'Trinidad Scorpion' did not differ significantly from 'Bhut Jolokia'. Molecular analysis with randomly amplified polymorphic DNA (RAPD) markers confirmed that the accessions are genetically unique. 'Trinidad Moruga Scorpion' belongs to the species C. chinense and is not the same chile pepper as 'Bhut Jolokia'.

$\longrightarrow$ hile peppers (Capsicum sp.) are cultivated worldwide and are often prized for their heat (Bosland and Votava, 2012). A widely used heat measurement for chile peppers is the SHU (Scoville, 1912). This measurement is the highest dilution of a chile pepper extract at which heat can be detected by a human taste panel. Alternative instrumental methods have been developed since Scoville's test. High-performance liquid chromatography (HPLC) is the most accurate and efficient method (Collins et al., 1995).

Chile pepper heat, or the amount of capsaicinoids (a group of alkaloids unique to Capsicum sp. that cause a burning sensation when eaten) in a chile pepper pod, is dependent on the genetic makeup of the plant and the environment where it is grown (Zewdie and Bosland, 2000a). The heat level can vary significantly among plants of the same variety grown in a single field

Department of Plant and Environmental Sciences, New Mexico State University, Las Cruces, NM 88003

A contribution of the New Mexico Agricultural Experiment Station, New Mexico State Univ., Las Cruces, NM 88003. We thank Dr. M. Herman Adams at the Caribbean Agriculture Research and Development Institute (CARDI) for sending the seed sample of 'Trinidad Scorpion', and Mr. Jim Duffy for sending seed samples of 'Trinidad Moruga Scorpion', 'Trinidad 7-pot Jonah', and 'Douglah Trinidad Chocolate'. We also thank Mr. Baolong Bai for assistance with the statistical analysis.

${ }^{1}$ Corresponding author. E-mail: pbosland@nmsu.edu. at the same time. When single plant heat levels of genetically identical chile pepper plants were compared with the field average, it was found that individual plants had heat levels as much as $78 \%$ higher than the field average, indicating the environment contributes significantly to chile pepper heat levels (Harvell and Bosland, 1997). Further research showed that fruit from different areas on the same plant had significantly different heat levels (Zewdie and Bosland, 2000b).

Heat level claims for chile peppers can be based on single fruit, single plants, or as an average of the variety as a whole. For the Guinness World Records, a single fruit is sufficient to set a record for some plants. However, for the chile pepper processing industry, an average heat level is more informative.

In 2007, Guinness World Records established 'Bhut Jolokia' chile pepper from the Assam region of northeastern India as being the world's hottest chile pepper. The heat level was established in replicated trials with appropriate controls (Bosland and Baral, 2007). The heat level of 'Bhut Jolokia' at 1,001,304 SHU, broke the million-SHU heat level for the first time.

A chile pepper variety, Trinidad Scorpion, from Trinidad and Tobago has been reputed to be hotter than 'Bhut Jolokia'. Currently, Guinness World Records recognizes 'Butch $\mathrm{T}$ Scorpion', grown by Butch Taylor in Australia, as the world's hottest chile pepper at 1,463,700 SHU (Guinness Book of World Records, 2011). Other varieties from Trinidad and Tobago (e.g., 'Trinidad Moruga Scorpion', 'Trinidad 7-pot Jonah', and 'Douglah Trinidad Chocolate') have been reported as very high heat varieties (Adams and Mohammed, 2008). Some of the variety names (i.e., 'Trinidad 7-pot Jonah') allude to folklore that they are hot enough to spice seven pots of soup.

To conduct a scientifically valid test to determine the mean heat level of a chile pepper variety, an ample seed sample must be planted in replicated trials that include an appropriate control. A random sample of fruit from the replicated varieties should then be tested. In this manner, a statistically higher heat level could reasonably be considered hotter than the current hottest variety.

This study was undertaken to 1 ) compare the heat levels of 'Trinidad Moruga Scorpion', 'Bhut Jolokia', 'Trinidad Scorpion', 'Douglah Trinidad Chocolate', and 'Trinidad 7-pot Jonah' in a replicated field trial; 2) establish which chile pepper variety truly has the highest average heat level; 3 ) determine any differences among the varieties across the environment; and 4) determine the genetic relatedness of the chile peppers using molecular data.

\section{Materials and methods}

The original seeds of 'Trinidad Scorpion' were sent to the Chile Pepper

\begin{tabular}{llll}
\hline $\begin{array}{l}\text { Units } \\
\text { To convert U.S. to SI, } \\
\text { multiply by }\end{array}$ & U.S. unit & SI unit & $\begin{array}{l}\text { To convert SI to U.S., } \\
\text { multiply by }\end{array}$ \\
\hline 0.3048 & $\mathrm{ft}$ & $\mathrm{m}$ & 3.2808 \\
2.54 & inch(es) & $\mathrm{cm}$ & 0.3937 \\
1.6093 & $\mathrm{mile}(\mathrm{s})$ & $\mathrm{km}$ & 0.6214 \\
28.3495 & $\mathrm{Oz}$ & $\mathrm{g}$ & 0.0353 \\
1 & $\mathrm{ppm}$ & ${ }^{\circ g} \cdot \mathrm{g}^{-1}$ & 1 \\
$\left({ }^{\circ} \mathrm{F}-32\right) \div 1.8$ & ${ }^{\circ} \mathrm{F}$ & ${ }^{\circ} \mathrm{C}$ & $\left(1.8 \times{ }^{\circ} \mathrm{C}\right)+32$
\end{tabular}


Institute in 2008 by $\mathrm{H}$. Adam at the Caribbean Agriculture Research and Development Institute in Trinidad and Tobago. 'Trinidad Scorpion' was grown under insect-proof net cages to produce the bulk seeds with the 2008 seed increase used in the replicated trials (Bosland, 1993). Seeds of 'Trinidad Moruga Scorpion', 'Trinidad 7-pot Jonah', and 'Douglah Trinidad Chocolate' were generously donated by J. Duffy of San Diego, CA. Fruit images in color of each accession can be seen at www.superhotchiles.com.

Seeds were sown into a planting medium (Metro-Mix 360; Sun Gro Horticulture, Bellevue, WA) in 12-celled bedding plant containers (Hummert Intl., Earth City, MO) that were placed into trays that hold eight 12-celled containers each and placed in a climatecontrolled greenhouse maintained at $82^{\circ} \mathrm{F}$ day $/ 65^{\circ} \mathrm{F}$ night $\left( \pm 11^{\circ} \mathrm{F}\right)$ with a 12 -h photoperiod. For each accession, two seeds per cell were sown, and after germination, seedlings were thinned to a single plant per cell. Each tray of 96 seedlings was fertilized with $\approx 1.5 \mathrm{~g}$ of $14 \mathrm{~N}-6.1 \mathrm{P}-11.6 \mathrm{~K}$ slowrelease fertilizer (Osmocote 14-1414; Scotts, Maysville, OH). Seedlings were watered twice per day.

In 2011, when seedlings had 8 to 10 true leaves, they were transplanted to field plots at the Leyendecker Plant Science Research Center, 1.5 miles south of Las Cruces, NM. A randomized complete block design with four replications with each replication having $\approx 36$ plants was accomplished. Plants were transplanted 10 inches apart in a single row with $3 \mathrm{ft}$ between rows. The plants were grown, including fertilizer applications, using standard cultural practices for growing chile peppers in southern New Mexico (Bosland and Walker, 2004).

Once the fruit had matured on the plants in the field, a single harvest of 25 random mature fruit from each of four plants in each of the four replications was accomplished. After harvest, the fruit sample was dried and ground to a uniform powder. The extraction of the capsaicinoids and the estimation of capsaicinoid amounts followed the HPLC procedures for the short run method as described by Collins et al. (1995). The HPLC data were converted from parts per million to SHU by multiplying the parts per million by 16 . Analysis of variance, least significant difference, and Duncan's multiple range test $(P \leq 0.05)$ determined the significance of the observed differences and were analyzed using the statistical software, SAS (version 9.2; SAS Institute, Cary, NC).

For RAPD analysis, one accession of Capsicum annumm ('Camelot') and six accessions of $C$. chinense ('Bhut Jolokia', 'Trinidad Scorpion', 'Trinidad 7-pot Jonah', and 'Douglah Trinidad Chocolate') were planted in I-gal plastic pots and grown in a greenhouse for DNA extraction.

When seedlings had 8 to 10 true leaves, six plants were randomly selected from each accession for DNA isolation. DNA extraction, quantification, polymerase chain reaction (PCR) amplification with RAPD markers, including the PCR thermal cycling profile used in this study are described by Baral and Bosland (2002). The RAPD primers used were OPA02, OPA04, OPA07, OPAl 1, OPA18, OPC02, OPC10, OPE12, OPF06, OPM04, OPAAl1, and OPP07 from Oligo 10-mer kits A, C, E, F, M, AA, and PP (Operon Technologies, Alameda, CA). Primer sequences are available by request. Presence or absence of RAPD bands was scored manually. If a RAPD band was present in a particular accession, it was scored as "l"; if the band was not present, it was scored as " 0. ." Band intensity was not taken into account. Molecular analysis was repeated.

The RAPD markers were analyzed by the computer software, numeric taxonomy, and multivariate analysis system [NTSYSpc 2.1 (Rohlf, 1998)]. Pairwise genetic similarity index was calculated by Nei and Li's Coefficient (Nei and Li, 1979): $S_{\mathrm{ij}}=2 N_{\mathrm{ij}} /\left(N_{\mathrm{i}}+\right.$ $N_{\mathrm{j}}$ ), where $N_{\mathrm{ij}}$ is the number of bands shared by the samples $i$ and $j . N_{i}$ and $N_{j}$ are the numbers of bands in samples $i$ and j, respectively. The similarity for qualitative (Simqual) data function of NTSYSpc 2.1 analyzed the RAPD data using Dice's similarity formula, which is the same as Nei and Li's coefficient (Dice 1945). A dendrogram was generated by means of the unweighted pair-group method with arithmetic averages using the sequential agglomerative, hierarchical and nonoverlapping clustering method (Sneath and Sokal, 1973).

\section{Results}

The growing season in 2011 was favorable for the production of fruit on all chile pepper varieties [daily maximum, minimum, and average temperatures for each day during the growing season are available from $\mathrm{New}$ Mexico State University (2012)]. Because the environment is known to affect the heat level of chile pepper varieties (Harvell and Bosland, 1997; Zewdie and Bosland, 2000a), having a replicated field trial with a control variety allows for the best comparison of heat levels among varieties. The HPLC analysis revealed that 'Bhut Jolokia' had a mean heat level of $1,019,687 \mathrm{SHU}$, which is in the range normally seen for this variety in Las Cruces, NM (Bosland and Baral, 2007). The results of the analysis for 'Trinidad Moruga Scorpion' indicated it also possessed an extremely high mean heat level, 1,207,764 SHU (Table 1).

Table 1. The mean heat level in Scoville heat units (SHU) for each block, overall mean, and highest individual plant for the five super hot chile pepper varieties.

\begin{tabular}{|c|c|c|c|c|c|c|}
\hline Variety & Block I & Block II & Block III & Block IV & Variety mean & $\begin{array}{c}\text { Highest } \\
\text { individual plant }\end{array}$ \\
\hline Trinidad Mor & $1,282,471 \mathrm{a}-\mathrm{d}^{\mathrm{z}}$ & $1,234,109 \mathrm{a}-\mathrm{d}$ & $1,360,772 \mathrm{ab}$ & 953,703 def & $1,207,764 \mathrm{~A}^{\mathrm{y}}$ & 2,00 \\
\hline Trinidad 7-pot Jonah & $1,051,778 \mathrm{~b}-\mathrm{f}$ & $1,014,364 \mathrm{c}-\mathrm{f}$ & $1,036,154 \mathrm{~b}-\mathrm{f}$ & $1,165,233 \mathrm{a}-\mathrm{e}$ & $1,066,882 \mathrm{AB}$ & $1,267,641$ \\
\hline Trinidad Scorpion & $1,076,204 a-f$ & $975,217 \mathrm{~d}-\mathrm{f}$ & 886,314 ef & $1,179,348$ a-e & $1,029,271 \mathrm{~B}$ & $1,392,452$ \\
\hline Bhut Jolokia & $1,115,052 a-f$ & $1,310,125 \mathrm{a}-\mathrm{c}$ & $869,051 \mathrm{ef}$ & $784,519 \mathrm{f}$ & $1,019,687 \mathrm{~B}$ & $1,578,548$ \\
\hline
\end{tabular}

${ }^{2}$ Different letters indicate significant differences $(P \leq 0.05)$ among varieties across all replications according to least significant difference test.

'Different letters within the column indicate significant differences $(P \leq 0.05)$ among varieties according to Duncan's test. 
'Trinidad Scorpion', 'Trinidad 7-Pot Jonah', and 'Douglah Trinidad Chocolate' also had high average heat levels of $1,029,271 ; 1,066,882$; and 1,169,058 SHU, respectively.

Significant variability in heat levels for the varieties across the field blocks was observed indicating an environmental effect on heat levels (Table 1, $P=0.0003)$. When the block averages across accessions were analyzed, a significant probability value of 0.0286 was obtained. The heat level of 'Bhut Jolokia' was significantly different between block II and block IV. Similarly, 'Trinidad Moruga Scorpion', Trinidad Scorpion', and 'Douglah Trinidad Chocolate' had heat levels that differed significantly between block III and block IV.

The variability in heat levels among individual plants was dramatic. When individual plants within the varieties were examined, a wide range of heat levels were observed: 'Trinidad Moruga
Scorpion' had two plants with heat levels higher than two million SHU (i.e., 2,009,231 and 2,006,598 SHU). The lowest heat level observed for 'Trinidad Moruga Scorpion' plant was 1,084,762 SHU. 'Douglah Trinidad Chocolate' single plant heat levels ranged from $1,853,936$ to 923,889 SHU, while 'Bhut Jolokia' ranged from a high of $1,578,548$ SHU to a low of 279,315 SHU. 'Trinidad Scorpion' had a range from $1,392,452$ SHU for the highest heat level to 801,180 SHU for the lowest heat level. For 'Trinidad 7-Pot Jonah', the highest heat level for a single plant was 1,262,641 SHU and the lowest heat level for an individual plant was 727,680 SHU.

When the overall mean heat levels of the varieties are examined, it was found that 'Trinidad Moruga Scorpion' had the highest heat level and was significantly hotter than 'Bhut Jolokia'. However, 'Trinidad Scorpion', 'Douglah Trinidad Chocolate', and
'Trinidad 7-Pot Jonah' were not significantly different from 'Trinidad Moruga Scorpion' nor were they significantly hotter than 'Bhut Jolokia'.

Because of interspecific comparisons between $C$. annumm and $C$. chinense varieties, the 12 oligonucleotide primers produced 114 reproducible polymorphic RAPD markers among the seven accessions of $C$. annumm and C. chinense. The molecular analysis was repeated, yielding the same results both times. The RAPD markers ranged in size from 1500 to 100 base pairs. There were 33 and 21 RADP markers unique to $C$. chinense and C. annumm, respectively.

The genetic similarities among the varieties were calculated by averaging the distances between clusters that are graphically presented in the form of a dendrogram in Fig. 1. Larger genetic similarity index values represent a closer taxonomic relation between clusters. There are two primary clusters

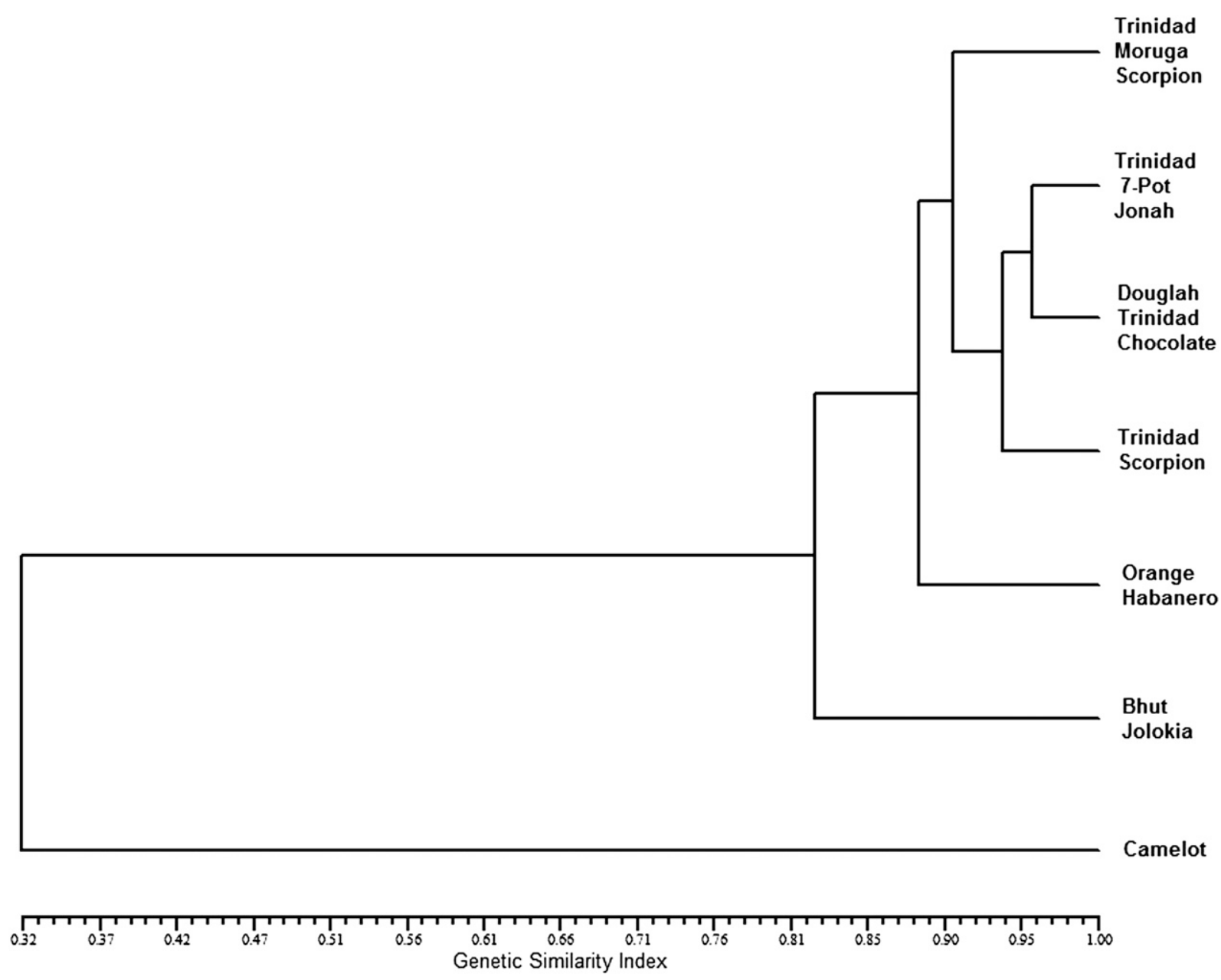

Fig. 1. Dendrogram based on the unweighted pair-group with arithmetic averages analysis of the Dice similarity coefficient among six Capsicum chinense accessions ('Trinidad Moruga Scorpion', 'Bhut Jolokia', 'Trinidad Scorpion', 'Douglah Trinidad Chocolate', and 'Trinidad 7-pot Jonah') and one Capsicum annum accession ('Camelot') using randomly amplified polymorphic DNA markers. 
that separate the Capsicum species (i.e., C. annumm and C. chinense). 'Camelot', the C. annuum accession in this analysis, formed a single cluster that grouped with the C. chinense accessions with a genetic similarity index value of 0.32 . 'Bhut Jolokia' grouped with the other $C$. chinense accessions with a genetic similarity index value of 0.82 , 'Orange Habanero' grouped together with 'Trinidad Moruga Scorpion', 'Trinidad 7-Pot Jonah', 'Douglah Trinidad Chocolate', and 'Trinidad Scorpion' with a genetic similarity index value of 0.89 . Likewise, 'Trinidad Moruga Scorpion' grouped with the accessions 'Trinidad 7-Pot Jonah', 'Douglah Trinidad Chocolate', and 'Trinidad Scorpion' with a genetic similarity index value of 0.91 . 'Trinidad Scorpion' grouped with 'Trinidad 7 Pot Jonah' and 'Douglah Trinidad Chocolate' at a genetic similarity index value of 0.94 . Finally, 'Trinidad 7-Pot Jonah' grouped with 'Douglah Trinidad Chocolate' with the highest genetic similarity index value of 0.96 .

\section{Discussion}

The results demonstrate that 'Trinidad Moruga Scorpion' can be considered the world's hottest known measured chile pepper (Fig. 2). Two 'Trinidad Moruga Scorpion' plants exceeded two million SHU, which is the first report of a chile pepper breaking the two million SHU level. Both 'Bhut Jolokia' and 'Douglah Trinidad Chocolate' had individual plants with heat levels greater than $1,463,700 \mathrm{SHU}$, exceeding the current Guinness World Records entry.

High variability in heat levels for individual plants for a given chile pepper accession and significant differences in mean heat level for the same variety between blocks were observed. Likely explanations for these observations are due to two facts 1) heat levels in chile peppers are heavily influenced by environment and 2) the varieties can be considered landraces (i.e., genetically heterogeneous) that do not behave uniformly.

The taxonomic relationship of 'Bhut Jolokia' to 'Trinidad Scorpion' based on RAPD markers places 'Bhut Jolokia' in a taxonomic position between $C$. annuum and the other $C$. chinense varieties. The reason the other $C$. chinense varieties show greater similarity is that 'Bhut Jolokia' is an interspecific hybrid that has C. frutescens genes introgressed into its genome (Bosland and Baral, 2007). The polymorphic bands generated from the 12 RAPD primers were enough to show genetic differences among the chile pepper varieties. Because RAPD markers are assumed to randomly sample the genome for polymorphisms, it is expected that further sampling would not alter the overall arrangement of the varieties based on relative genetic variation very much (Votava and Bosland, 2002). Thus, from the genetic similarity index values, it can be concluded that 'Bhut Jolokia' is not a 'Trinidad Scorpion' variety grown in India or that 'Trinidad Scorpion' is a parent of 'Bhut Jolokia'. Instead, they appear to be unique varieties. Furthermore, none of the pepper varieties from Trinidad and Tobago are likely to be the parent of 'Bhut Jolokia'. The genetic similarity indexes among 'Trinidad 7-Pot Jonah', 'Douglah Trinidad Chocolate', and 'Trinidad Scorpion' were the closest. Strong genetic similarities among these varieties may be explained by the fact that they are open-pollinated landraces from the same island of Trinidad. It has been reported that cross-pollination in chile peppers can occur as frequently as $90 \%$ and as infrequently as $2 \%$ (Bosland and Votava, 2012). However, it is concluded that

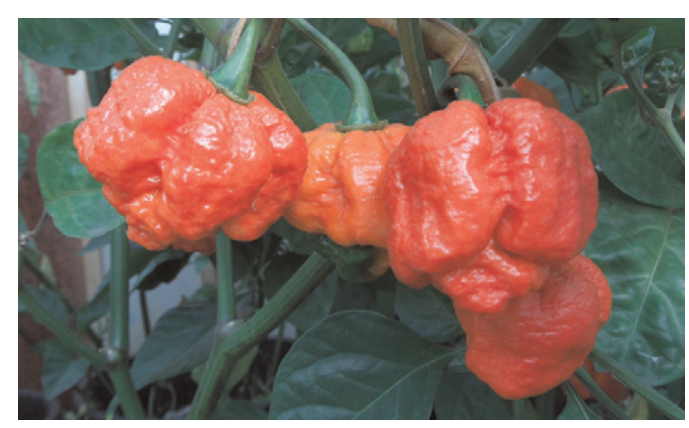

Fig. 2. Fruit of 'Trinidad Moruga Scorpion' chile pepper.

these are unique varieties because there was observed genetic separation among them.

The results of this study confirm that heat can fluctuate greatly among chile pepper varieties cultivated in the same location. Identification of highheat chile pepper varieties will likely aid genetic characterization of pungency in Capsicum sp. Moreover, highheat chile pepper varieties offer a better source for capsaicinoid extraction for various uses.

Seeds of 'Trinidad Scorpion' and 'Bhut Jolokia' are available through the Chile Pepper Institute, P.O. Box 30003, MSC 3Q, New Mexico State University, Las Cruces, NM 88003.

\section{Literature cited}

Adams, H. and K. Mohammed. 2008. A catalogue of the commercial hot pepper landraces of Trinidad and Tobago. Caribbean Agr. Res. Dev. Inst. PSC\#TT/001/ 08 .

Baral, J. and P.W. Bosland. 2002. Genetic diversity of a Capsicum germplasm collection from Nepal as determined by randomly amplified polymorphic DNA markers. J. Amer. Soc. Hort. Sci. 127: 316-324.

Bosland, P.W. 1993. An effective plant field-cage to increase the production of genetically pure chile (Capsicum sp.) seed. HortScience 28:1053.

Bosland, P.W. and E.J. Votava. 2012. Peppers: Vegetable and spice capsicums. CABI, Wallingford, UK.

Bosland, P.W. and J. Baral. 2007. 'Bhut Jolokia'-The world's hottest known chile pepper is a putative naturally occurring interspecific hybrid. HortScience $42: 222-224$

Bosland, P.W. and S. Walker. 2004. Growing chiles in New Mexico. New Mexico State Univ. Coop. Ext. Guide H-230.

Collins, M.D., L.M. Wasmund, and P.W. Bosland. 1995. Improved method for quantifying capsaicinoids in Capsicum using high-performance liquid chromatography. HortScience 30:137-139.

Dice, L.R. 1945. Measures of the amount of ecological association between species. Ecology 26:297-302.

Guinness Book of World Records. 2011. Hottest Chili (sic). 29 May 2012. <www. guinnessworldrecords.com>.

Harvell, K.P. and P.W. Bosland. 1997. The environment produces a significant 


\section{Preliminary and Regional Reports}

effect on pungency of chiles (Capsicum annumm L.). HortScience 32:1992.

Nei, M. and W.H. Li. 1979. Mathematical model for studying genetic variation in terms of restriction endonucleases. Proc. Natl. Acad. Sci. USA 123:925-930.

New Mexico State University. 2012. Monthly weather reports. 29 May 2012. <http://aces.nmsu.edu/academics / pes/monthly-weather-reports.html>.
Rohlf, F.J. 1998. Numerical taxonomy and multivariate analysis system (NTSYSpc): Ver.2.0. Exeter Publication, Setauket, NY.

Scoville, W.L. 1912. Note on capsicum. J. Amer. Pharmaceutical Assn. 1:453-454.

Sneath, P.H.A. and R.R. Sokal. 1973. Numerical taxonomy. Freeman, San Francisco.

Votava, E.J. and P.W. Bosland. 2002. A cultivar by any other name: Genetic vari- ability in heirloom bell pepper 'California Wonder'. HortScience 37:1100-1102.

Zewdie, Y. and P.W. Bosland. 2000a. Evaluation of genotype, environment, and genotype-by environment interaction for capsaicinoids in Capsicum annuиm L. Euphytica 111:185-190.

Zewdie, Y. and P.W. Bosland. 2000b. Pungency of chile (Capsicum annumm L.) fruit is affected by node position. HortScience 35:1174. 